\title{
A Novel High-performance Electrospun Thermoplastic Polyurethane/Poly(vinylidene fluoride)/Polystyrene Gel Polymer Electrolyte for Lithium Batteries
}

\author{
Yuanyuan Deng, Zeyue He, Qi Cao*, Bo Jing, Xianyou Wang and Xiuxiang Peng \\ Key Laboratory of Environmentally Friendly Chemistry and Applications of Minister of Education, \\ College of Chemistry, Xiangtan University, Xiangtan 411105, China \\ *Corresponding author: E-mail: wjcaoqi@ 163.com \\ Received: 06-09-2016
}

\begin{abstract}
A novel high-performance gel polymer electrolyte (GPE) based on poly(vinylidene fluoride) (PVDF), thermoplastic polyurethane (TPU) and polystyrene (PS) has been prepared. Its characteristics are investigated by scanning electron microscopy (SEM), thermal analysis (DSC), universal testing machines (UTM), galvanostatic charge-discharge and electrochemical impedance spectroscopy. The GPE based on TPU/PVDF/PS (10 wt.\%) show a high ionic conductivity of $5.28 \times 10^{-3} \mathrm{~S} \mathrm{~cm}^{-1}$ with the electrochemical stability window of $5.0 \mathrm{~V}$. In addition, its first charge-discharge capacity reached to $169.5 \mathrm{mAh} \mathrm{g}^{-1}$, high mechanical strength and stability to allow safe operation in rechargeable lithium ion polymer batteries.
\end{abstract}

Keywords: Gel polymer electrolytes; Electrospinning; Poly (vinylidene fluoride); Polystyrene; Thermoplastic polyurethane

\section{Introduction}

Polymer-based nanocomposites have attracted considerable academic and industrial attention over the years. ${ }^{1,2}$ Various combinations of polymer matrices and nanofillers have been investigated. It is known to us that superior performance of lithium ion battery is determined by active electrode materials and excellent electrolytes. Among them, gel polymer electrolytes (GPEs) have been reported with high ionic conductivity at room temperature, stable and well compatibility with lithium electrodes, ${ }^{3-5}$ and good mechanical stability. There are many ways to produce GPEs such as phase inversion method, $\gamma$-ray irradiation method, solvent casting technique, thermally induced phase separation technique, and electrospinning technique.$^{6-8}$ In these methods, electrospinning technique which made the solution of polymer into lots of uniform and slender nanofibers under high voltage is a simple, controllable and efficient approach. Thermoplastic polyurethane (TPU) contains two-phase microstructure which are soft segments and hard segments. ${ }^{9-11}$ The hard sections are incompatible with the soft section in thermodynamics, while these two phases are interconnec- ted throughout each other. The whole system benefits from these two phases since that the hard parts afford spatial stability and the soft phases are conducive to good ionic conductivity owing to the soft segments don't form ionic cluster after being dissolved alkali metal salt. Many investigations were devoted to copolymerizing TPU with other polymers for processing GPEs. Some articles based on coaggregant like thermoplastic polyurethane (TPU)/linear poly (ethylene oxide) (PEO) (TPU-PEO), thermoplastic polyurethane (TPU)/polyacrylonitrile (PAN) (TPU$\mathrm{PAN}$ ) and polyurethane/poly (vinylidene fluoride) (PUPVDF) as GPEs for rechargeable lithium batteries have been reported lately. ${ }^{12-14}$ Different concentrations of thermoplastic polyurethanes/poly(vinylidene fluoride-co- hexafluoro propylene) (TPU/PVDF-HFP) derived from some researchers including our study group member Xiuxiang Peng having done related research. ${ }^{15}$ Poly (vinylidene fluoride) (PVDF) is a semi-crystalline polymer. ${ }^{16}$ With low water absorption, high mechanical properties and interfacial stability with lithium metal, ${ }^{17-19}$ PVDF has been adopted as polymer electrolyte in lithium ion polymer batteries. ${ }^{20}$ Polystyrene (PS) polymers possess excellent mechanical properties: high strength, fatigue resistance 
and dimension stability. Besides, it also has high glass transition temperature and high dielectric breakdown field. From the properties of the three kinds of materials, each of these three kinds of materies is very appropriate as a gel polymer matrix.

Our group have done some research, which was the first trial of making TPU/PVDF/PS fiber membranes..$^{21} \mathrm{In}$ comparison to PU/PVDF, TPU/PS and PVDF/PS films, the TPU/PVDF/PS films show more noticeable electrochemical characteristic and mechanical performance. We would like to continue our efforts to develop TPU/PVDF/ PS porous fibrous films by electrospinning using different concentration polymer solutions. In order to investigate the influence of various polymer concentration stresses on the TPU/PVDF/PS fiber membranes, membrane morphology, charge and discharge capacity, ionic conductivity, and mechanical properties will be examined systemically. In this study, we expect to provide a deep investigation and insight on the preparation of TPU/PVDF/PS microporous fiber membranes with prominent electrochemical and mechanical performance. Primary results showed that it is very suitable for application in lithium ion batteries.

\section{Experimental}

\section{1. Materials}

Thermoplastic polyurethane (TPU, yantaiwanhua, 1190A), polystyrene (PS,yangzishihua) and poly( vinylidene fluoride) (PVDF, Alfa Aesar) were dried under vacuum at $80{ }^{\circ} \mathrm{C}$ for $24 \mathrm{~h} . \mathrm{LiClO}_{4} \cdot 3 \mathrm{H}_{2} \mathrm{O}$ (AR, Sinopharm Chemical Reagent Co., Ltd.) was dehydrated in vacuum oven at $120^{\circ} \mathrm{C}$ for $72 \mathrm{~h} .1 .0 \mathrm{M}$ Liquid electrolyte was made by dissolving a certain quality of $\mathrm{LiClO}_{4}$ in ethylene carbonate (EC, Shenzhen capchem technology Co., Ltd.)/propylene carbonate (PC, Shenzhen capchem Technology Co. Ltd.) (1/1, v/v). N, N-dimethylforamide (DMF) and acetone were analytical purity and used as received without further treatment.

\section{2. Preparation of TPU/PVDF/PS fibrous Membrane}

In the first place, a certain amount of dried PVDF, TPU and PS $(6: 6: 1, \mathrm{wt} / \mathrm{wt} / \mathrm{wt})$ were dissolved in the mixture of acetone/ $\mathrm{N}, \mathrm{N}$-dimethylacetamide $(1: 3, \mathrm{wt} / \mathrm{wt})$ forming a $9 \mathrm{wt} . \%$ solution, then they were stirred by mechanical stirring for $12 \mathrm{~h}$ at room temperature. Then $10 \mathrm{wt} . \%$, $11 \mathrm{wt} . \%, 12 \mathrm{wt} . \%$ TPU/PVDF/PS solutions were made by the same way. After being stayed for 10 minutes to remove air bubbles, the viscous blending polymer solution was put into the needle injection pump. The tip of the needle was connected to high voltage source $(24.5 \mathrm{kV})$ and electrospined at ambient atmosphere. Porous fibrous films were obtained on the collector plate. The electrospun po- rous fibrous films were finally dried under vacuum at 80 ${ }^{\circ} \mathrm{C}$ for $12 \mathrm{~h}$.

\section{3. Preparation of Gel Polymer Electrolytes}

The thickness of the TPU/PVDF/PS nonwoven films used was about $100 \mu \mathrm{m}$. At room temperature, the dried TPU/PVDF/PS nonwoven films were activated by $1 \mathrm{M}$ $\mathrm{LiClO}_{4}-\mathrm{EC} / \mathrm{PC}$ liquid electrolyte solutions for $1 \mathrm{~h}$ in a glove box filled with argon. Wipe the surface of swelled membranes by filter paper and then get the gel polymer electrolytes.

\section{4. Membrane Characterization}

Scanning electron microscope (SEM, Hitachi S$3500 \mathrm{~N}$, Japan) was used to examine the morphology of the films. The thermal stability of the films was monitored using thermogravimetric analysis (model TQAQ 50, TA Company, USA). DSC measurements were carried out under the temperature range from $20-200^{\circ}$ at a scan rate of $10 \% \mathrm{~min}$. The mechanical strength of the gel polymer electrolyte films was measured by universal testing machines (UTM, Instron Instruments). There are some difficulties in surveying the "wet" films (with electrolyte), therefore the test was measured the mechanical properties of the "dry" membrane (without electrolyte). The extension rate was kept at $5 \mathrm{~mm} \mathrm{~min}^{-1}$. The dimensions of the sheet used were $2 \mathrm{~cm} \times 5 \mathrm{~cm} \times 150-250 \mu \mathrm{m}$ (width $\times$ length $\times$ thickness). The porosity was investigated by immersing the membranes into n-butanol for $1 \mathrm{~h}$ and then calculated by using the following relation:

$$
P=\frac{W_{W}-W_{d}}{\rho_{b} V_{p}} \times 100 \%
$$

$W_{w}$ and $W_{d}$ are the mass of the wet and dry membrane, respectively, $\tilde{n}_{b}$ is the density of n-butanol, and $V_{p}$ is the volume of the dry membrane.

The electrolyte uptake was determined by measuring the weight increase and calculated according to Eq:

$$
\text { Uptake }(\%)=\frac{W-W_{0}}{W_{0}} \times 100 \%
$$

$W_{0}$ is the weight of dried films and $\mathrm{W}$ is the weight of swelled films.

The ionic conductivity of the composite film was measured with SS/PE/SS blocking cell by AC impedance measurement using Zahner Zennium electrochemical analyzer with a frequency range of $0.1-1 \mathrm{MHz}$. The thin films were prepared about $100 \mu \mathrm{m}$ in thickness and $1.96 \mathrm{~cm}^{2}$ in area for impedance measurement. Thus, the ionic conductivity could be calculated from the following equation:

$$
\sigma=\frac{h}{R_{b} S}
$$


In Eq. (3), $\sigma$ is the ionic conductivity, $R_{b}$ is the bulk resistance, $h$ and $S$ are the thickness and area of the films, respectively.

\section{5. Cell Assembly and Performance Characteristics}

Electrochemical stability was measured by a linear sweep voltammetry (LSV) of a Li/PE/SS cell using Zahner Zennium electrochemical analyzer at a scan rate of $5 \mathrm{mV} \mathrm{s}^{-1}$, with voltage from $2 \mathrm{~V}$ to $6 \mathrm{~V}$. For charge-discharge cycling tests, the $\mathrm{Li} / \mathrm{PE} / \mathrm{LiFePO}_{4}$ cell was assembled. The cell was subjected to electrochemical performance tests using an automatic charge-discharge unit, Neware battery testing system (model BTS-51, ShenZhen, China), between 2.5 and $4.2 \mathrm{~V}$ at $25^{\circ} \mathrm{C}$, at different current densities.

\section{Results and Discussion}

\section{1. Morphology and Structure}

Fig. 1 shows the SEM images of the membranes prepared by electrospinning of different concentrations of 9 to $12 \mathrm{wt} \%$ TPU/PVDF/PS polymer solution. All of these four membranes show a microporous structure, but we can see that the fibers of TPU/PVDF/PS (Fig.1(b)10 wt.\%) are relatively uniform and slender, with the diameter distribution about $1 \mu \mathrm{m}$. While the fibers of TPU/PVDF/PS (Fig.1 (a)9 wt.\%) are cross linked unevenly in the middle part of it. Both of the fibers of TPU/PVDF/PS (Fig.1(c)11 wt.\%) and (Fig.1(d)12 wt.\%) diameter distribution values are thicker than the fibers of TPU/PVDF/PS (Fig.1(b)10 wt.\%), so do the fiber smoothness.

From the principle of electrospinning we know there are many factors that can affect fiber membranes' morphology. The parameters influencing the morphology of electrospun fiber membranes contain the distance between the nozzle of the syringe and the collector, the applied voltage, dielectric constant of the solution and the concentration of the polymer solution. In this work, the only difference is the concentration of the polymer solution. Finally, we found that TPU/PVDF/PS polymer solution of $10 \mathrm{wt} . \%$ is the best for electrospinning. After blending, there is interface between different materials. The interfacial interation force which has a great influence on the morphology of electrospinning film, the greater the force, the poorer the performance of membrane. The interface force is the minimum when the mass fraction is $10 \%$, which is why the membranes of TPU/PVDF/PS (10 wt.\%) is smooth and slender.
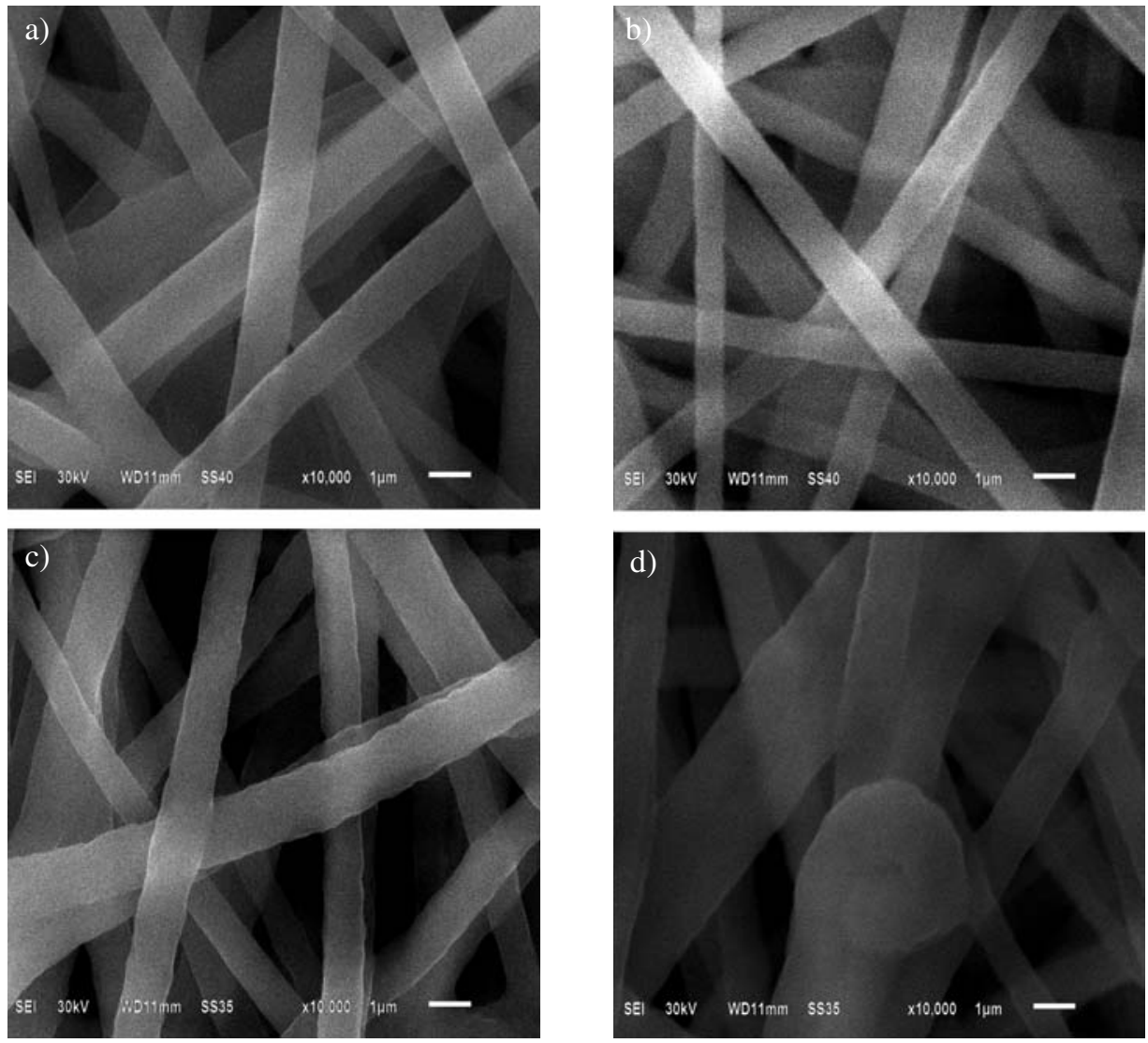

Fig. 1. SEM images of TPU/PVDF/PS electrospun membranes (a) 9 wt.\% (b) 10 wt.\% (c) 11 wt.\% (d) 12 wt.\% 


\section{2. DSC Analysis}

Typical DSC curves of the nanofibrous membranes varied with the relative weight of PVDF/TPU/ PS, which are presented in Fig.2. From the Table 1, the crystallinity of TPU/PVDF/PS (9 wt.\%) is $20.43 \%$; the crystallinity of TPU/PVDF/PS (10 wt.\%) is $13.64 \%$; the crystallinity of TPU/PVDF/PS (11 wt.\%) is $21.37 \%$; the crystallinity of TPU/PVDF/PS (12 wt.\%) is $26.65 \%$. We can find that the crystallinity decreased when concentration increased from $9 \mathrm{wt} . \%$ to $10 \mathrm{wt} . \%$. However, with the concentration continuing to increase, the crystallinity gets enlargement. So we can get a conclusion that $10 \mathrm{wt} . \%$ concentration has the lowest degree of crystallinity.

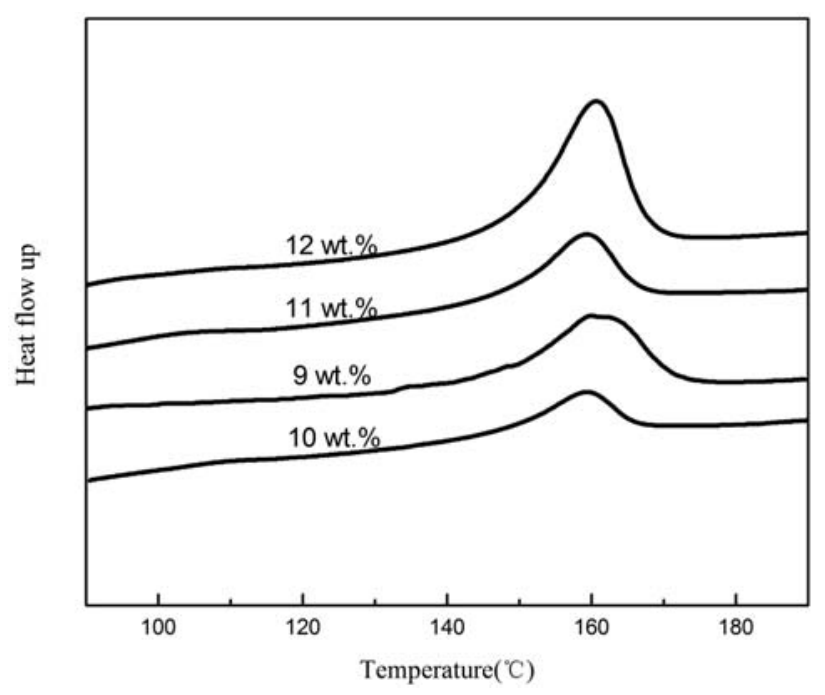

Fig. 2. DSC thermograms of different concentration of TPU/ VDF/PS

Table 1. Thermodynamic properties of different concentration of TPU/PVDF/PS

\begin{tabular}{lcc}
\hline Sample & $\Delta \mathbf{H}_{\mathbf{f}}(\mathbf{J} / \mathbf{g})$ & Crystallinity $\boldsymbol{\chi}_{\mathbf{c}}(\boldsymbol{\%})$ \\
\hline TPU/PVDF/PS (9 wt.\%) & 8.91 & 20.43 \\
TPU/PVDF/PS (10 wt.\%) & 6.61 & 13.64 \\
TPU/PVDF/PS (11 wt.\%) & 11.39 & 21.37 \\
TPU/PVDF/PS (12 wt.\%) & 15.5 & 26.65 \\
\hline
\end{tabular}

\section{3. Electrolyte Uptake and Ionic Conductivity}

Fig. 3 shows the uptake behaviors of the electrospun fibrous membranes. The percentage of electrolyte uptake can be calculated according to Eq(A). The TPU/PVDF/PS (9 wt.\%) fibrous film shows an electrolyte uptake of about $310 \%$ within $2 \mathrm{~min}$, The TPU/PVDF/PS(10 wt.\%) fibrous film is $331 \%$, The TPU/PVDF/PS (11 wt.\%) fibrous film is $296 \%$, The TPU/PVDF/PS (12 wt.\%) fibrous film is $274 \%$ after $15 \mathrm{~min}$, it is found that the electrolyte uptake of these four membranes become stabile. The uptake of the electrolyte solution reaches up to $320 \%$ ( 9 wt.\%), $341 \%$ (10 wt.\%), 305\% (11 wt.\%), 298\% (12 wt.\%), respectively. The absorption of large quantities of liquid electrolyte by the composite membranes results from the high porosity of the membranes and the high amorphous content of the polymer. The fully interconnected pore structure makes fast penetration of the liquid into the membrane possible, and hence the uptake process is stabile within the initial $15 \mathrm{~min}$. TPU/PVDF/PS (10 wt.\%) membrane owns the highest porosity, so it also has the highest electrolyte uptake percentage. Furthermore, the TPU/ PVDF/PS (10 wt.\%) membrane's average fiber diameter is minimal that leads to the increasing in the absorption ratio of the electrolyte solution. Because the porosity and the surface area of the pore wall of the film will increasing with the average fiber diameter decreasing. The increasing of surface area of the pore wall and more pores result in a higher uptake of the liquid electrolyte, which means more $\mathrm{Li}^{+}$in the same volume. ${ }^{22}$

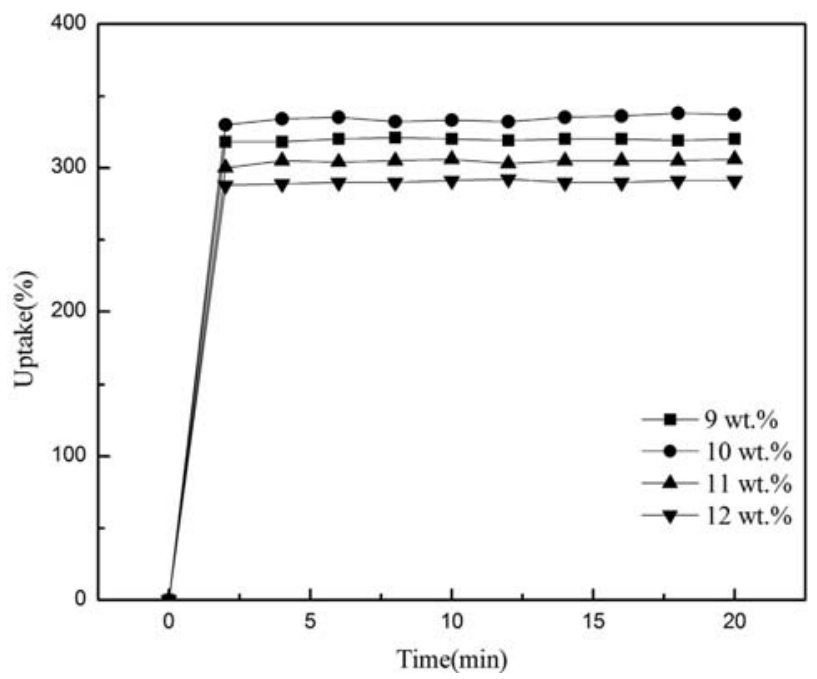

Fig. 3. The uptake behavior of the TPU/PVDF/PS electrospun fibrous films

Fig.4 shows the impedance spectra of TPU/PVDF/ PS based fibrous polymer electrolyte. It is typical AC impedance for gel polymer electrolyte. The self-resistance (R) is the major contribution to the total resistance and ionic conductivity is calculated according to Eq.(3). The ionic conductivity of TPU/PVDF/PS (10 wt.\%) membrane was $5.28 \times 10^{-3} \mathrm{mS} \mathrm{cm}^{-1}$ at room temperature. From table 2 , we know that the ionic conductivity of TPU/PVDF/PS (10 wt.\%) membrane is maximal, and the body resistance of TPU/PVDF/PS (10 wt.\%) membrane is the smallest. The solution crystallinity, porosity and absorption rate have relationships with the self-resistance, from the previous experimental results we can know why the ionic conductivity of TPU/PVDF/PS (10 wt.\%) membrane is the biggest. 
Table 2. Different concentration of TPU/PVDF/PS membranes' parameters and ionic conductivity

\begin{tabular}{lcccc}
\hline Materials & $\mathbf{R b}(\boldsymbol{\Omega})$ & $\mathbf{H}(\mathbf{c m})$ & $\mathbf{S}\left(\mathbf{c m}^{-\mathbf{2}}\right)$ & $\mathbf{\sigma}\left(\mathbf{1 0}^{-\mathbf{3}} \mathbf{S ~ c m}^{\mathbf{- 1}}\right)$ \\
\hline TPU/PVDF/PS (9 wt.\%) & 2.92 & 0.0014 & 2.02 & 2.37 \\
TPU/PVDF/PS (10 wt.\%) & 1.12 & 0.0012 & 2.03 & 5.28 \\
TPU/PVDF/PS (11 wt.\%) & 4.67 & 0.0014 & 1.98 & 1.51 \\
TPU/PVDF/PS (12 wt.\%) & 5.2 & 0.0012 & 2.05 & 1.13 \\
\hline
\end{tabular}

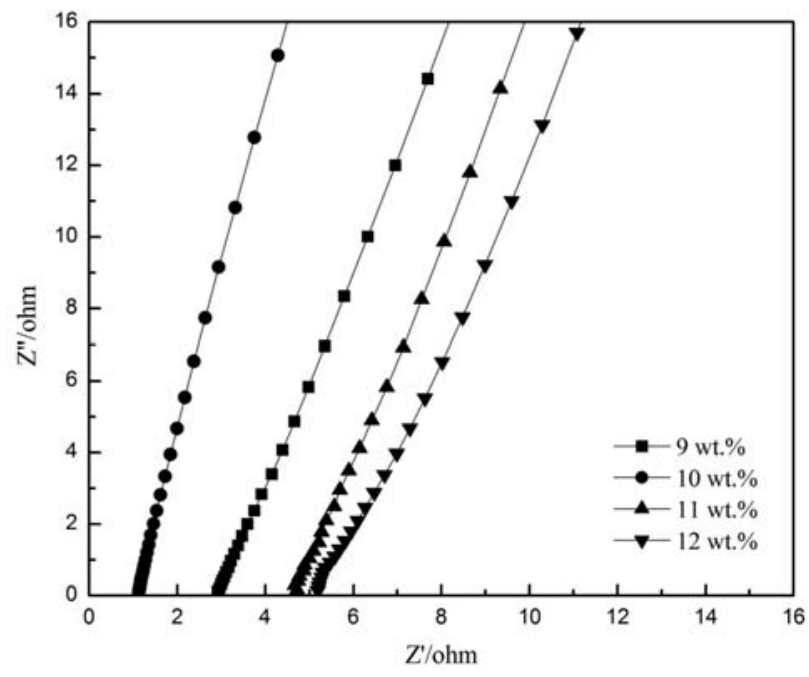

Fig. 4. Impedance spectra of gel polymer electrolytes

\section{4. Evaluation in $\mathrm{Li} / \mathrm{LiFePO}_{4}$ Cell}

Fig. 5 shows the first charge-discharge capacity curves of the cells with GPEs of TPU/PVDF/PS. The GPEs of TPU/PVDF/PS (10 wt.\%) delivers a charge capacity of $169.81 \mathrm{mAh} \mathrm{g}^{-1}$ and discharge capacity of $169.5 \mathrm{mAh} \mathrm{g}^{-1}$, which is about $99 \%$ of the theoretical capacity. The GPEs of TPU/PVDF/PS (9 wt.\%; 11 wt.\%; 12 wt.\%) deliver a charge capacity of $161.79 \mathrm{mAh} \mathrm{g}^{-1} ; 159.49 \mathrm{mAh} \mathrm{g}^{-1}$;

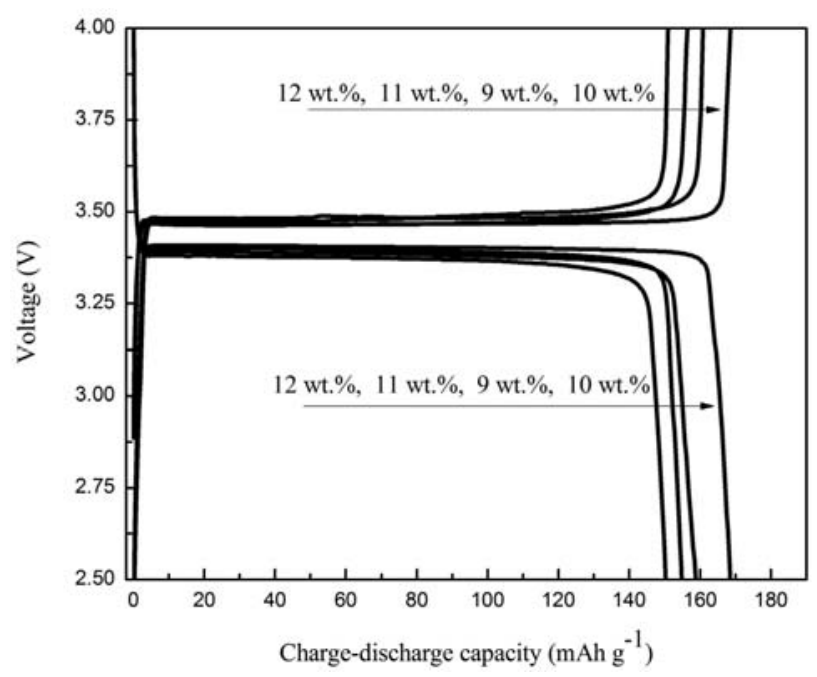

Fig. 5. first Charge-discharge capacity of different concentration of GPEs based on electrospun TPU/PVDF/PS membrane

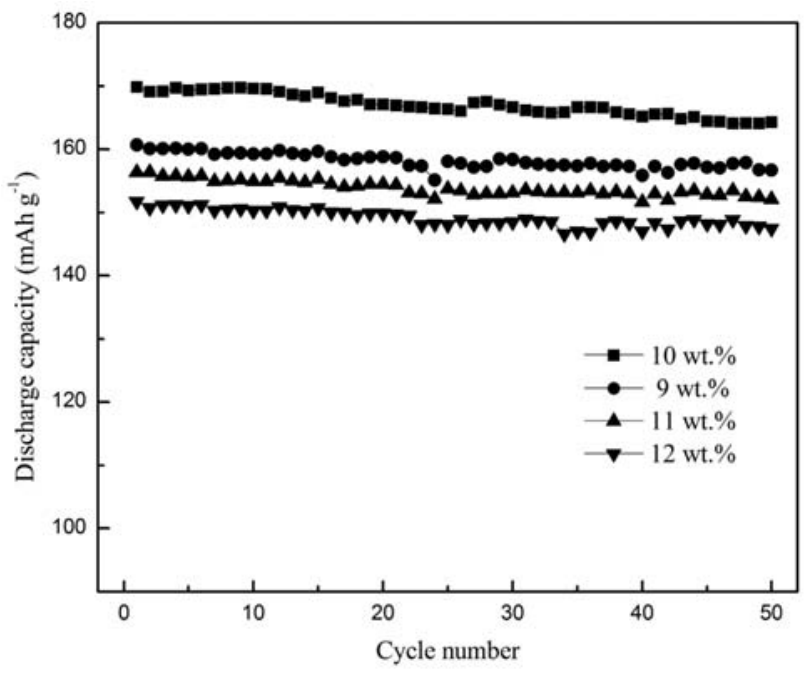

Fig. 6. The cycle performance (discharge capacitie) of different concentrations of GPE based on electrospun TPU/PVDF/PS membranes

$151.82 \mathrm{mAh} \mathrm{g}^{-1}$ and discharge capacity of $160.65 \mathrm{mAh} \mathrm{g}^{-1}$; $156.32 \mathrm{mAh} \mathrm{g}^{-1} ; 151.74 \mathrm{mAh} \mathrm{g}^{-1}$. The Li cells with GPEs have been evaluated for cycle ability property under the 0.1 $\mathrm{C}$ rate at $25^{\circ} \mathrm{C}$ and the results are shown in Fig. 6. The cell with GPE (10 wt.\%) has a highest discharge capacities in the whole 50 cycles. From the above data, we can know that the GPEs of TPU/PVDF/PS (10 wt.\%) owns the best charge-discharge capacity and cycle ability property.

\section{5. Mechanical Property}

The stress-strain curves of different concentrations of electrospun PVDF/TPU/PS membranes are presented in Fig. 7, and their mechanical properties are summarized in Table 3. Because no phase separation of the nanofibrous membranes was observed from SEM, the nanofibrous membranes presented acceptable mechanical properties to be applied into practice. ${ }^{23}$ It can be found that PVDF/TPU/PS (10 wt.\%) membrane owns the longest elongation of $98.2 \%$ and can bear the tensile strength below 12.9 MPa. Both the tensile strength and elongation are better than others. Because electrospun membranes are constituted by three kinds of polymer, all of three kinds of polymer are dissolved in the mixture of acetone/ $N, N$-dimethylacetamide (1:3, wt/wt) solution, and there is interfacial force between each others. As we know that the PVDF/TPU/PS (10 wt.\%) membrane's interfacial 


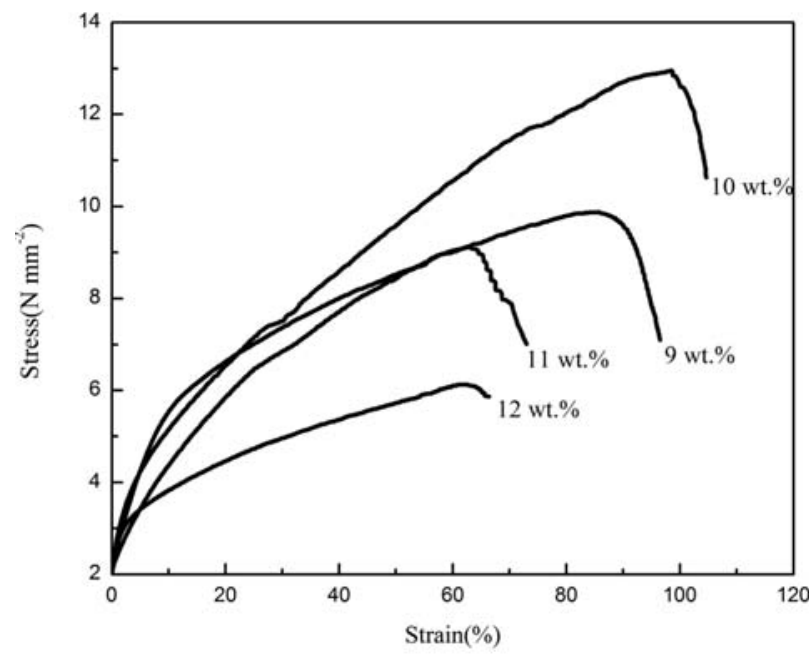

Fig. 7. Stress strain curves of different concentration of electrospun PVDF/TPU /PS membranes

Table 3. Mechanical properties of different concentration of electrospun PVDF/TPU /PS

\begin{tabular}{lcc}
\hline Samples & Stress (Mpa) & Strain (\%) \\
\hline TPU/PVDF/PS (9 wt.\%) & $9.9 \pm 0.2$ & $85.4 \pm 0.2$ \\
TPU/PVDF/PS (10 wt.\%) & $11.9 \pm 0.2$ & $94.2 \pm 0.2$ \\
TPU/PVDF/PS (11 wt.\%) & $9.14 \pm 0.2$ & $63.2 \pm 0.2$ \\
TPU/PVDF/PS (12 wt.\%) & $6.16 \pm 0.2$ & $62.8 \pm 0.2$ \\
\hline
\end{tabular}

force is the smallest, so do the crystallinity of PVDF/TPU/PS (10 wt.\%) membrane. The greater the degree of crystallinity, the worse of the toughness. So the PVDF/TPU/PS (10 wt.\%) membrane has the best mechanical properties.

\section{6. Electrochemical Stability}

The results of electrochemical stability tests of the gel polymer electrolytes by LSV are shown in Fig.8. From Fig.8, the electrochemical stability of the gel polymer electrolyte with PVDF/TPU/PS (10 wt.\%) membrane is 4.9 V. And their electrochemical stability follows the order: TPU/PVDF/PS (10 wt.\%) 4.9 V> TPU/PVDF/PS (11 wt.\%) 4.3 V> TPU/PVDF/PS (9 wt.\%) $4.0 \mathrm{~V}>$ TPU/ PVDF/PS (12 wt.\%) 3.6 V. It is clearly that the gel polymer electrolyte of TPU/PVDF/PS (10 wt.\%) shows the best electrochemical stability, which may due to better compatibility with liquid electrolyte and nanofibrous membranes with less leakage of liquid electrolytes. In addition, the electrochemical stability was also influenced by the large and fully interconnected pores, high porosity, higher specific surface area, uniform morphology of membranes and the AFD. From the SEM images of TPU/PVDF/PS electrospun membranes you can know that the gel polymer electrolyte of TPU/PVDF/PS (10 wt.\%) possesses high porosity and surface area. Therefore

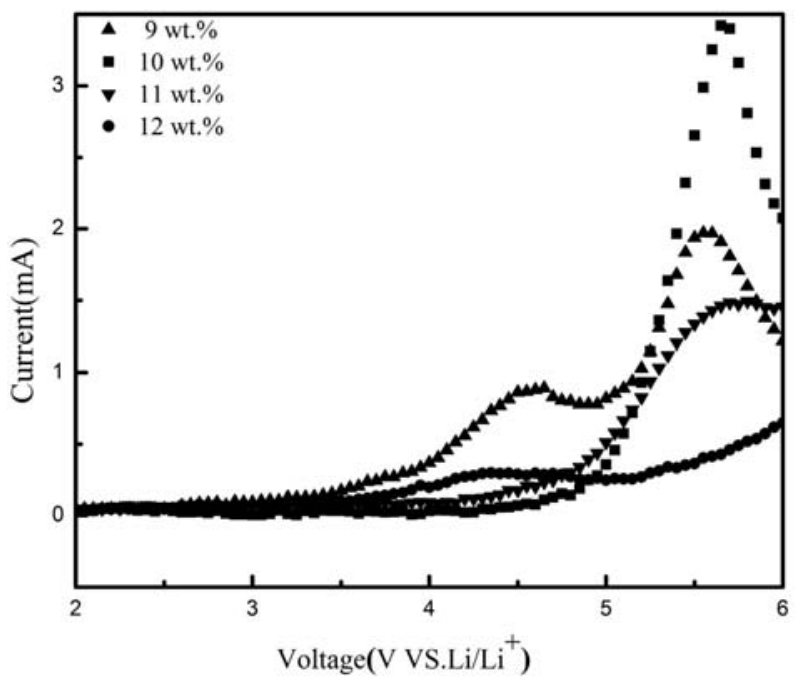

Fig. 8. Linear sweep voltammograms of the gel polymer electrolytes

the gel polymer electrolyte of TPU/PVDF/PS (10 wt.\%) is best for applications in lithium-ion.

\section{Conclusions}

GPEs based on fibrous TPU/PVDF/PS blend membranes were prepared by electrospinning the polymer solution in DMF/acetone $(3: 1, \mathrm{w} / \mathrm{w})$ at room temperature. It has been observed that the optimum proportion of a novel high-performance gel polymer electrolyte is TPU/PVDF/ PS (10 wt.\%). It has a high ionic conductivity of $5.28 \times$ $10^{-3} \mathrm{mS} \mathrm{cm}^{-1}$ with electrochemical stability up to $5.0 \mathrm{~V}$ versus $\mathrm{Li}^{+} / \mathrm{Li}$ at room temperature. The first charge-discharge capacity of gel polymer electrolyte lithium battery based on PVDF/TPU/PS (10 wt.\%) is about $169.5 \mathrm{mAh}$ $\mathrm{g}^{-1}$ at $25^{\circ}$. The PDVF/TPU/PS (10 wt.\%) mixed film owns the longest elongation of $98.2 \%$, and it can bear the tensile strength below $12.9 \mathrm{MPa}$. Both the tensile strength and elongation are excellent. The PVDF/TPU/PS (10 wt.\%) based gel polymer electrolyte is the optimum proportion of a novel high-performance gel polymer electrolyte for rechargeable lithium batteries.

\section{Acknowledgements}

The workers gratefully appreciate the financial supports from the Youth Project of National Nature Science Foundation of China (No. 51203131).

\section{References}

1. Zhu YS, Wang FX, Liu LL, Xiao SY, Chang Z, Wu YP, Energy Environ. 2013, 6, 618-624. 
https://doi.org/10.1039/C2EE23564A

2. Theron SA, Zussman E, Yarin AL, J. polymer. 2004, 45, 2017-2030.

3. J. J. Xu, H. Ye, Electrochem. Commun. 2005, 7, 829-835. https://doi.org/10.1016/j.elecom.2005.04.034

4. S.-I. Kim, H.-S. Kim, S.-H. Na, S.-I. Moon, Y.-J. Kim, N.-J. Jo, Electrochim. Acta. 2004, 50, 317-321. https://doi.org/10.1016/j.electacta.2003.12.068

5. N. Wu, B. Jing, Q. Cao, X. Wang, H. Kuang, Q. Wang, J. Appl. Polym. Sci. 2012, 125, 2556-2563. https://doi.org/10.1002/app.36523

6. C. R. Yang, Z. D. Jia, Z. C. Guan, L. M. Wang, J. Power Sources. 2009, 189, 716-720. https://doi.org/10.1016/j.jpowsour.2008.08.060

7. P. Raghavan, J. W. Choi, J. H. Ahn, G. Cheruvally, G. S. Chauhana, H. J. Ahn, C.Nah, J. Power Sources. 2008, 184, 437-443. https://doi.org/10.1016/j.jpowsour.2008.03.027

8. R. Prasanth, N. Shubha, H. H. Hng, M. Srinivasan, J. Power Sources. 2014, 245, 283-291. https://doi.org/10.1016/j.jpowsour.2013.05.178

9. M. Digar, S.-L. Hung, H.-L. Wang, T.-C. Wen, A. Gopalan, Polymer. 2002, 43, 681-691. https://doi.org/10.1016/S0032-3861(01)00655-3

10. J. Van Heumen, J. Stevens, Macromolecules. 1995, 28, 4268-4277. https://doi.org/10.1021/ma00116a030

11. H.-H. Kuo, W.-C. Chen, T.-C. Wen, A. Gopalan, J. Power Sources, 2002, 110, 27-33. https://doi.org/10.1016/S0378-7753(02)00214-8

12. Y.-L. Du, T.-C. Wen, Mater, Chem. Phys. 2001, 71, 62-69. https://doi.org/10.1016/S0254-0584(01)00271-1
13. P. Santhosh, T. Vasudevan, A. Gopalan, K.-P. Lee, Mater. Sci. Eng. B. 2006, 135, 65-73. https://doi.org/10.1016/j.mseb.2006.08.033

14. Ten-Chin Wen, Han-Hsin Kuo, A. Gopalan, Solid State Ionics. 2002, 147, 171-180.

15. X. X. Peng, L. Zhou, Q. Cao, J. Solid State Electrochem. 2016, 20, 255-262 https://doi.org/10.1007/s10008-015-3030-5

16. N. Wu, Q. Cao, X. Wang, Q. Chen, Solide State Ionics. 2011, 203, 42-46. https://doi.org/10.1016/j.ssi.2011.08.020

17. W. W. Cui, D. Y. Tang, Z. L. Gong, J. Power Sources. 2013 , 223, 206-213. https://doi.org/10.1016/j.jpowsour.2012.09.049

18. Y. S. Zhu, S. Y. Xiao, Y. Shi, Y. Q. Yang, Y. P. Wu, J. Mater. Chem. A. 2013, 1, 7790-7797. https://doi.org/10.1039/c3ta00167a

19. L. Zhou, N. Wu, Q. Cao, B. Jing, X. Y. Wang, Q. Wang, H. Kuang, Solid State Ionics. 2013, 249-250, 93-97. https://doi.org/10.1016/j.ssi.2013.07.019

20. S. S. Sekhon, H. P. Singh, Solide State Ionics. 2002, 169, 152-153.

21. X. L. Tang, Q. Cao, X. Y. Wang, X. X. Peng, J Zeng, RSC $A d v ., 2015,5,58655-58662$

22. L. Zhou, Q. Cao, B. Jing, X. Y. Wang, X. L. Tang, N. Wu, J. Power Sources. 2014, 263, 118-124. https://doi.org/10.1016/j.jpowsour.2014.03.140

23. W. L. Li, Y. H. Wu, J. W. Wang, D. Huang, L. Z. Chen, European Polymer Journal. 2015, 67, 365-372. https://doi.org/10.1016/j.eurpolymj.2015.04.014

\section{Povzetek}

Pripravili smo visoko učinkovit gel polimerni elektrolit (GPE), ki temelji na polivinilidenfluoridu (PVDF), termoplastičnem poliuretanu (TPU) in polistirenu (PS). Njegove lastnosti smo preučevali z naslednjimi tehnikami: vrstično elektronsko mikroskopijo (SEM), termično analizo (DSC), meritvami mehanskih lastnosti (UTM) in elektrokemijsko impedančno spektroskopijo. Gel polimerni elektroliti (GPE), ki temeljijo na TPU/PVDS/PS (10 wt.\%) imajo visoko ionsko prevodnost $5.28 \times 10^{-3} \mathrm{~S} \mathrm{~cm}^{-1}$ in elektrokemijsko okno stabilnosti 5.0 V. Poleg tega pa prva kapaciteta polnjenja in praznjenja doseže $169.5 \mathrm{mAh} \mathrm{g}^{-1}$. Zaradi dobrih mehanskih lastnosti in stabilnosti bi bili ti materiali lahko uporabni v litij ionskih polimernih baterijah. 